\title{
Long-term Retention of Many Visual Patterns by Pigeons
}

\author{
Lorenzo von Fersen \& Juan D. Delius
}

\begin{abstract}
Using a simultaneous discrimination procedure it was shown that pigeons were capable of learning to discriminate 100 different black and white visual patterns from a further 625 similar stimuli, where responses to the former were rewarded and responses to the latter were not rewarded. Tests in which novel stimuli replaced either the rewarded or nonrewarded stimuli showed that the pigeons had not only learned about the 100 positive stimuli but also about the 625 negative stimuli. The fact that novel stimuli enhanced discrimination performance when they replaced the many negative stimuli indicated that the pigeons had categorized the stimuli into two classes, familiar and less familiar. Long-term retention was examined after a 6-month interval. To begin with it seemed poor but a recognition test performed after the subjects had been retrained with a subset of the stimuli after an interval of 7 months confirmed that pigeons are capable of retaining in memory several 100 visual items over an extended period. It is proposed that the initial retrieval weakness was due to a forgetting of the contingencies between stimulus categories and response outcomes. Further tests involving variously modified stimuli indicated that while stimulus size variations had a negative effect on performance, orientation changes did not interfere with recognition, supporting the view that small visual stimuli are memorized by pigeons largely free of orientation labels. The experiment generally confirms that pigeons have the capacity of storing information about a large number of visual stimuli over long periods of time.
\end{abstract}

Corresponding author: Prof. Dr. J. D. Dritus, Allgemeine Psychologie, Universität Konstanz, Postfach 5560, D-7750 Konstanz.

\section{Introduction}

It is generally agreed that an extensive and lasting memory is an essential prerequisite for any kind of advanced processing of information by organisms and machines. That the behaviour of humans is largely controlled by large and stable stores of acquired knowledge is undisputed. It is equally likely that animals would profit in fitness if they had command over similar information. However formal evidence that they possess extensive and persistent storage capacities is still scarce. 
Most animal memory studies have thus far been mainly focused on shortterm retention of information using the delayed matching-to-sample procedure. During the retention interval the subjects have to remember a sample stimulus (or stimuli) so that they can later choose correctly among comparison stimuli. Pigeons can retain such information for up to $1 \mathrm{~min}$ (Honig 1978; Kraemle \& ROBERTS 1984; RoBerTS \& GRANT 1976; Wright et al. 1985). This compares with 2 to 3-min delays that are bridged, for example, by dolphins and monkeys (Herman 1980; D’Amato 1973; D'Amato \& Worsham 1974). Pigeons can also retain more complex information over somewhat longer periods $(5 \mathrm{~min})$ as has been shown in the context of several spatial memory tests (OLSON \& MAKI 1983; RoberTs \& Van VLLDHUIZEN 1985; SPETCH \& Edwards 1986). They thus appear to be inferior to rats on such tasks, which can bridge up to $30 \mathrm{~min}$ (OlToN 1978).

It is traditional in human work to distinguish short-term (or working) memory and long-term (or reference) memory (ATKINSON \& SHII?RIN 1968; RoITBLAt 1987). The distinction is particularly apparent in the so-called "serial position curves" that plot the retention of a list of items. Depending on experimental conditions the first and/or last items of such lists are better remembered than those presented in the middle. The recency effect (referring to the better retention of the last items) is said to be due to a short-term trace whereas the primary effect is said to be due to transfer to long-term storage. WRIGHT et al. (1985) demonstrated that both effects are similarly shown by humans, monkeys and pigeons, although with somewhat different time constants. This implies that the distinction between working and reference memory is valid for animals as well as humans.

Comparatively few studies have been conducted on long-term memory proper of animals. Several instances of simple task retention in vertebrates have been summarized by RENSCH (1973). Titmice and nutcrackers can remember the location of many food-hoards over intervals of hours to days (SHETTLEwORTH 1983; Sherry 1984; VAN DER Wall 1982). Starlings which had experience with artificial Batesian mimicry models still avoided them 4 months later (SCHULER 1974). Pigeons remember instrumentally conditioned skills over months to years (Donahoe \& Marrs 1982; SkinNer 1950; SChwartz \& Reilly 1985) much as monkeys do (Treichler 1984; BURdyn et al. 1984).

The theme of the present contribution is the long-term memorization of larger amounts of pictorial information. Several studies have demonstrated the remarkable capacity of humans for storing such information. A classic one is SHEPARD's (1967) in which subjects were shown 612 stimuli for a few s each. In subsequent tests they had to discriminate between the familiar and novel stimuli. Even after 120 days recognition performance was above chance (see also NickeRSON 1968; STANDING 1973 for similar findings with many more stimuli). RINGO \& DOTY (1985) found that rhesus monkeys correctly recognized about a third of a set of visual stimuli they had seen briefly 6 months before. Provided that the pictorial items were chosen so as to make a verbal coding unlikely, monkeys and humans showed similar memory performance (RINGO et al. 1986).

Pigeons also have a remarkable capacity for retaining considerable amounts of visual information over a long period. VAUGHAN \& GRTENE (1984), using both 
simple squiggles and complex scenes as stimuli, carried out several relevant experiments. The most salient result was that pigeons, trained to discriminate 160 pairs of slides, classified these at an above chance level even after 2 years. An experiment done by I. MOHR and S. SCHÜRGER in our laboratory produced concurring results (Delius 1985). 8 pigeons were gradually trained to distinguish up to 100 repeatedly presented geometric-decorative patterns from 640 patterns that were shown at most twice using a successivc discrimination paradigm. $\Lambda \mathrm{fter}$ a pause of 3 months the birds recognized the familiar stimuli almost as well as after intervals of 2 days.

The present experiment was designed to explore the influence of some procedural modifications and to test particular aspects of the pigeons' memory using similar pictorial items as in the experiment mentioned last. Certain unexpected results led to the formulation of novel hypotheses about the representation of visual stimuli in pigeon long-term memory.

\section{Methods \\ Subjects}

Four adult pigeons (Columba livia) of local homing stock were employed. They had cxtensive previous experience with visual discrimination tasks. While participating in the present experiment the subjects were housed in single cages in a well ventilated room with a temperature of $18^{\circ} \mathrm{C}$ and with a

Fig. 1: Schema of the apparatus employed (top); detail of the working-area (bottom)
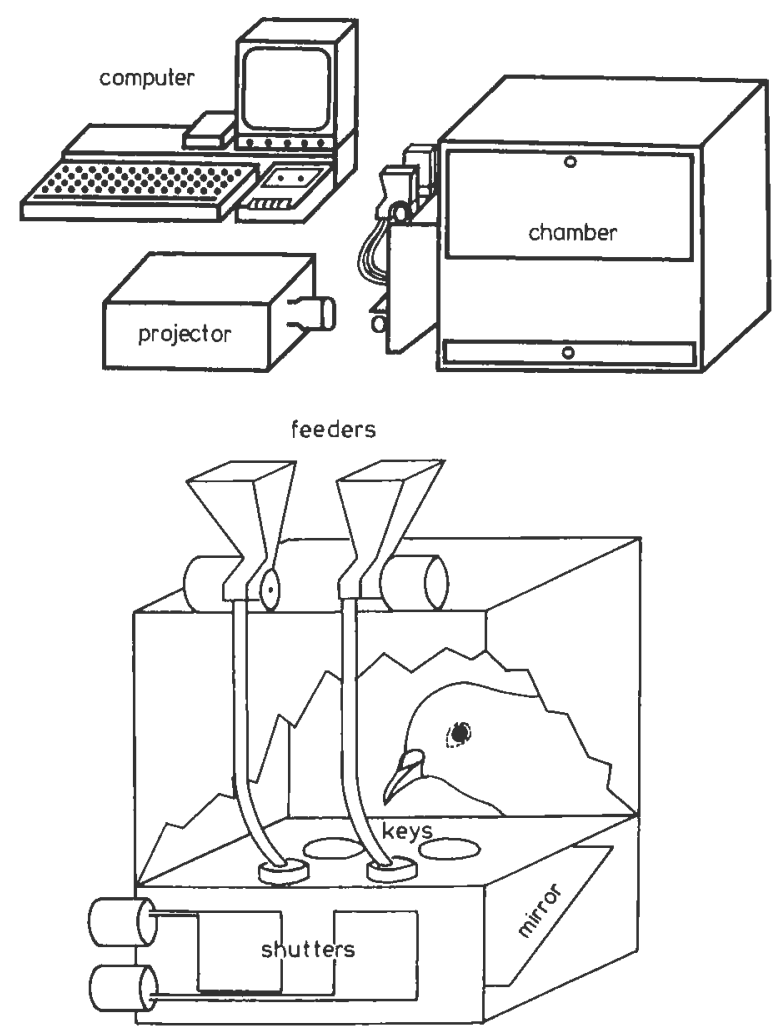
light/dark cycle of $14 / 10 \mathrm{~h}$. Throughout the experiment the pigeons were maintained at $80 \%$ of free feeding weight. During an experimental pause to be mentioned later the pigeons were kept in an outside aviary and were allowed to regain their full weight.

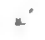

\section{Apparatus}

A modified two-key Skinner box was employed (Fig. 1). The chamber measured $33 \times 34 \times 33 \mathrm{~cm}$. Its front wall had an opening of $11 \times 12.5 \mathrm{~cm}$ above the floor. A houselight was located $5 \mathrm{~cm}$ above this opening. A horizontal working surface measuring $12 \times 9 \mathrm{~cm}$ was attached outside and level with the lower edge of the opening. It was surrounded by an enclosure measuring $16 \times 14 \times 10 \mathrm{~cm}$.

Two keys made of translucent perspex (22 mm diameter) were positioned side by side on the horizontal surface, with their centres separated by $90 \mathrm{~mm}$. Immediately in front of the keys were two reward receptacles. On the roof of the alcove were two automatic feeders that, when activated, delivered a few grains of millet to the receptacles through lengths of tubing. A reward light was attached to the ceiling of the alcove. A mirror placed at an angle of $45^{\circ}$ below the keys deflected the beam of a projector onto the two keys. Two electromagnetic shutters enabled the projection of stimuli onto the two keys.

An automatic projector and specially made slides were employed to display the stimuli on the keys. The stimuli were small white and black photographic negatives of 975 patterns originally drawn in black ink on white paper. They were part of a larger collection of decorative geometric shapes routinely used in our laboratory. The reduced negatives were affixed to the slide frames two at a time. On the keys the patterns appeared as white shapes of about $10 \mathrm{~mm}$ diameter on a dark background. The frames also had three coding holes that could be individually covered with masking tape. The code was read by photocells within the projector.

A microcomputer (Commodore VC 20) equipped with a special interface and programmed with a Basic extensidn that allows a convenient on-line control (Psychobasic by F. vON MUNNCHOw POHL) controlled all the events within an experimental session. It also recorded and printed out the results on a trial by trial basis.

\section{Training}

The animals were trained to peck both keys with a conventional autoshaping method. When shaping was complete after 730 -min sessions, discrimination training proper began.

Two daily sessions were conducted, each consisting of 40 trials. Within a given trial the leftright position of the positive and negative stimuli was determined by a quasi-random sequence (GELLERMANN 1933). A total of 725 stimuli were used during this phase (Fig. 2). 100 of these were randomly allocated to the class "few" (positive) and the remaining 625 to the class "many" (negative). The pairs of shapes, each consisting of a "few" and a "many" stimulus were assembled randomly. If the animal responded to the key bearing the positive shape the stimuli went off and the subject was rewarded with 4 to 6 grains of millet, signalled by a brief flash of the reward light. After an intertrial interval of $3 \mathrm{~s}$ the next trial began with the presentation of a new pair of shapes. If an animal responded to the negative stimulus, both shapes and the houselight were obscured for $5 \mathrm{~s}$. After such an error the same patterns were presented again (correction trial), and if necessary this was repeated until the animal made a correct response. As the subjects became experienced the within trial response requirements were gradually increased. Eventually the subjects had to issue 16 consecutive correct pecks to obtain a reward whereas 16 incorrect responses, not necessarily performed consecutively led to time-out.

The animals began training with a selection of 30 " $\mathrm{few}^{\mathrm{N}}$ stimuli. As they reached criterion $(80 \%$ correct choices or better over 10 consecutive sessions) the number of "few" stimuli was increased by 10 until the animals dealt with all of the 100 "few" stimuli. These stimuli were always presented in the same standard orientation (Fig. 2). All 625 "many" shapes though were used from the beginning onwards. They were randomly presented in either of two different orientations, normal as illustrated in Fig. 2 or rotated by $180^{\circ}$ around an axis normal to the picture plane. Through the training the individual negative patterns were thus used every 15.5 sessions while the individual positive patterns were initially reused every 0.75 sessions and finally only every 2.5 sessions. The training phase run according to this procedure lasted 224 sessions. 

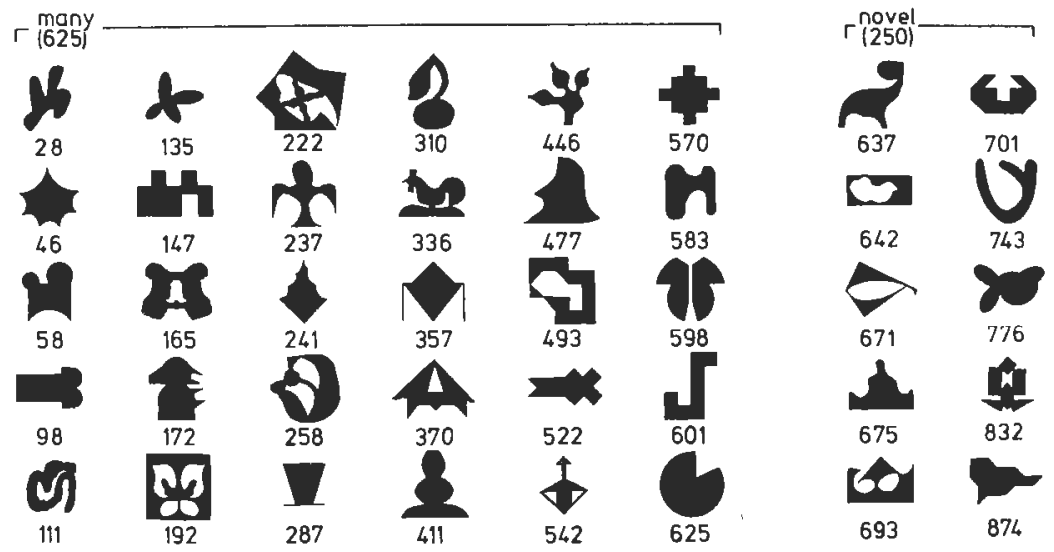

Fig. 2: Examples of patterns employed, classified according to the three relevant classes

An additional 20 sessions were conducted to prepare the aninals for tests. Some trials within these sessions were not reinforced, that is neither reward nor time-out was given. These trials led directly to the intertrial interval with no correction procedure in force. The number of these extinction trials was gradually increased until a session contained 14 of them. The extinction trials were inserted at random within the sessions, excepting the first five and the last five trials.

\section{Tests}

Test series comprised 10 sessions of 40 trials each. Each such session contained 10 extinction trials involving the presentation of test stimuli pairs. Between these series the birds were retrained for 10 or 15 normal sessions. For the first test series the pairs presented during the test trials had the stimulus of the class "many" replaced by one of 100 novel stimuli. The next test series involved an analogous replacement of "few" stimuli by novel stimuli. 50 of the patterns had in fact been used as non-reinforced stimuli in the previous test (they were quasi-novel). The other 50 were completely novel. The third test series, intended as a control, involved replacing both the "few" and "many" stimulus classes of test trials by completely novel stimuli. Only 5 test trials per session were inserted during this last test series and thus required 100 new shapes.

The next 3 test series involved rotating "few" stimuli by $180^{\circ}$ in three different ways. Stimuli were either rotated around their vertical axis, around their horizontal axis or around an axis normal to the picture plane, 10 sessions with each kind of test trials were run. The stimuli to be rotated were randomly selected except that no stimulus was rotated twice within a series. All 100 "few" shapes stimuli were thus successively presented in all three test conditions. The stimuli belonging to the class "many" were not expressly rotated during tests, because they were anyway presented in two different orientations (see above) throughout the experiment, including the training, retraining and test phases.

Two test series were run in which the size of the "few" and "many" stimuli was altered. In one series the size of both shapes displayed on the keys during the test trials was about $5 \mathrm{~mm}$ in diameter (original size $10 \mathrm{~mm}$ diameter). Exactly the same procedure was then used with shapes increased in size to $20 \mathrm{~mm}$.

\section{Retention}

Having completed these 8 test series and after a final retraining phase the animals were housed in a large outside aviary. After 6 months they were brought back into the laboratory and again deprived of food to $80 \%$ of their normal weight. After a pause of 187 days, retraining began using only 60 of the "few" stimuli and 585 of the "many" stimuli. The response requirements were gradually increased to the modified fixed ratio of 16 within the first 5 sessions. All the trials were reinforced or punished as in the previous training sessions. When the birds had achieved a mean of $80 \%$ correct responses over " 10 consecutive sessions they had one session where they were presented with the remaining 40 pairs of stimuli (40 "few" and 40 "many" shapes), which they had not seen for 222 days. 
Retraining for 15 sessions followed. The carlier tests in which the stimuli of the class "many" were replaced by novel stimuli and those where the stimuli "few" were replaced by novel stimuli were repeated following the same procedure as described before. Instead of totally novel stimuli, quasinovel stimuli that had been used once in previous extinction test trials some 8 months before were employed.

\section{Results}

Performance during training of each individual was evaluated by calculating the percentage of correct responses per session (excluding correction trials). Two separate percentages were calculated for sessions including test trials, one for the test trials and one for the remaining training trials. One of the four pigeons exhibited a very low response rate and was excluded from the experiment after 50 training sessions. The remaining three pigeons needed 47,66 and 72 sessions to discriminate the first 50 "few" stimuli from the 625 "many" stimuli to a criterion of $80 \%$ correct choices. The same subjects only needed a mean of 22.1 (range $17.0-31.0$ ) sessions to reach criterion after the addition of the last two sets of 10 "few" stimuli.

Fig. 3 summarizes the results for the critical stages of training. For the acquisition of the first 30 "few" stimuli the average percent correct responses for the first 15 sessions and the last 5 sessions until criterion are illustrated. For the

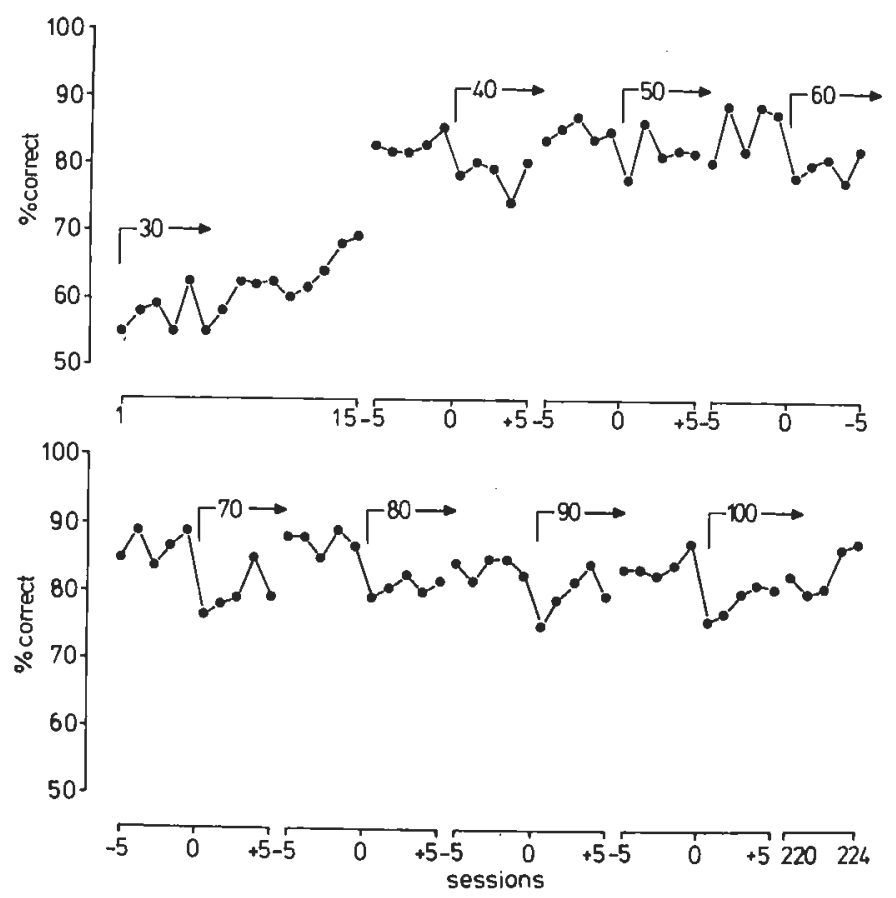

Fig. 3: Mean performance of 3 pigeons during the acquisition phase. The performance during the initial sessions (with 30 "few" stimuli), before and after the introduction of additional "few" stimuli and during the terminal sessions is depicted 


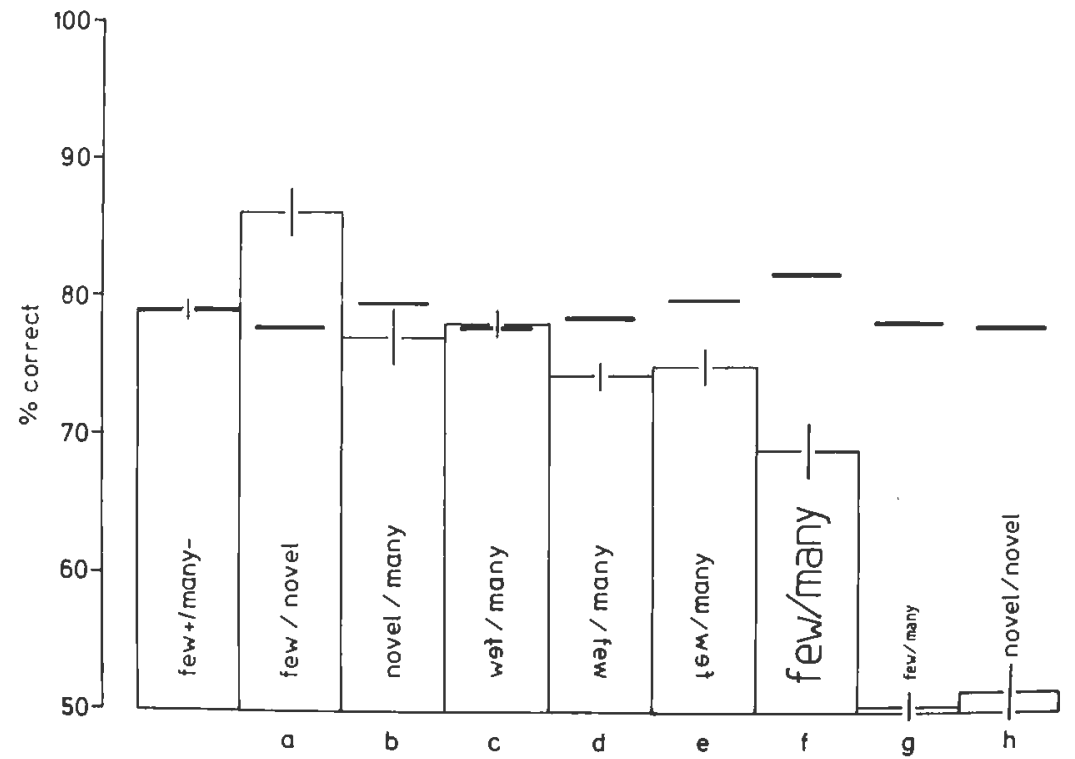

Fig. 4: Average overall performance (with SD) during the terminal block of acquisition sessions and during the various blocks of test scssions involving upside-down and right-left reflections, enlargement and reduction. Horizontal bars indicate the performance on the training conponent of the corresponding test sessions

remaining stages the average performance for the first 5 sessions following introduction of 10 additional "few" stimuli and the last 5 sessions until criterion are shown. The pigeons needed 162,181 and 224 sessions respectively to learn to discriminate to criterion the 100 "few" stimuli from the 625 "many" stimuli. The two fastest pigeons continued to receive training until they too had completed 224 sessions. At this stage the subjects only exceptionally went through more than a single correction trial after errors.

The test results are presented in Fig. 4 in the form of an overall average performance score. In Figs, 5 to 7 a more detailed session by session account is presented. It is obvious that when "many" stimuli were replaced by novel stimuli the discrimination performance improved $(85.7 \%$ compared with $77.5 \%$ trials correct for the corresponding training trials; $(\mathrm{F}[1,38]=9.27, \mathrm{p}<.01 ;$ Figs. 4 a, $5)$.

For the test in which the "few" stimuli were replaced by novel stimuli three separate performance indices can be calculated. They involve the training trials (overall average over the 10 sessions: $79.4 \%$ correct), the test trials with quasinovel shapes that had been seen once by the pigeons as non-reinforced stimuli in the previous test series $(78.2 \%$ trials correct) and the test trials in which the shapes were totally new $(75.4 \%$ correct). Percentages correct in the last two kinds of test trials were not significantly different. Accordingly they are pooled in Figs. $4 \mathrm{~b}$ and 5. In fact, there are no significant differences amongst any of the three conditions $(F[2,58]=1.08, p>.05)$. This result indicates that the pigeons 


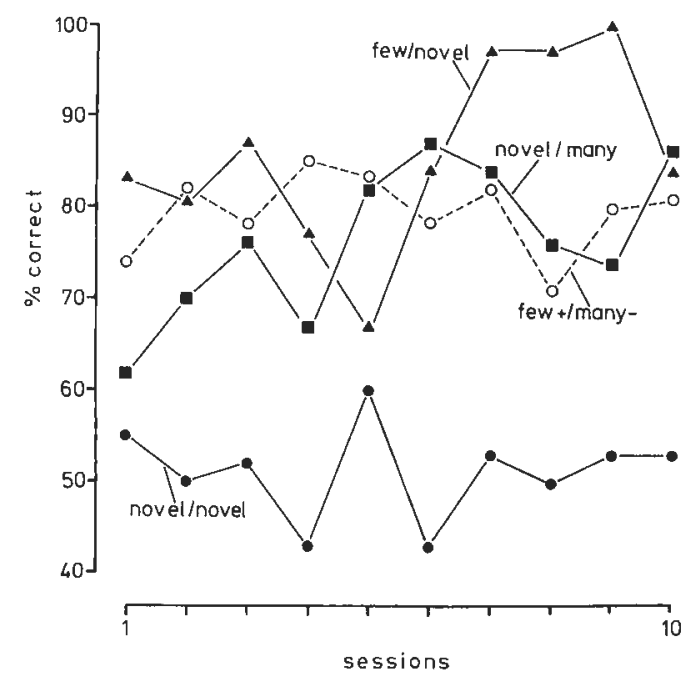

Fig. 5: Mean performance of 3 pigeons during the test sessions involving novel stimuli. + and - refer to the training component

had not only memorized the 100 "few" shapes, and learned to peck them, but that they also had stored most of the 625 "many" shapes (presented in two different orientations), and had learned to withhold pecks to them.

The simultaneous replacement of both stimuli ("few" and "many") yielded a significant performance difference between test and training trials $(F[1,38]=$ $38.98, \mathrm{p}<.001$; Figs. $4 \mathrm{~h}$ and 5 ). The average percentage of correct responses during the test trials was $51.3 \%$, which was not significantly different from $50 \%$ chance performance (binomial test, $\mathrm{z}=0.69, \mathrm{p}>.05$ ) whereas on training trials performance was $77.5 \%$ correct. This test shows that when neither of the shapes of a pair gave a cue to the pigeons they chose at random. Thus it can be assumed that generally their choice behaviour was not guided by any unintended artefactual cues.

Fig. 6: Mean performance during test sessions involving shape orientation variations ( 3 separate orientation test serics are shown averaged together)

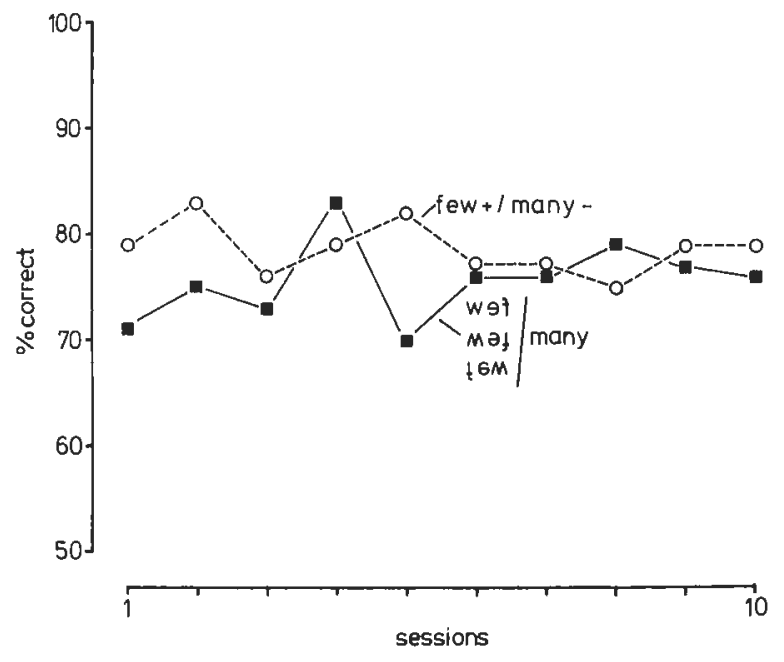


Fig. 7: Mean performance of 3 pigcons during test sessions involving varying shape sizes

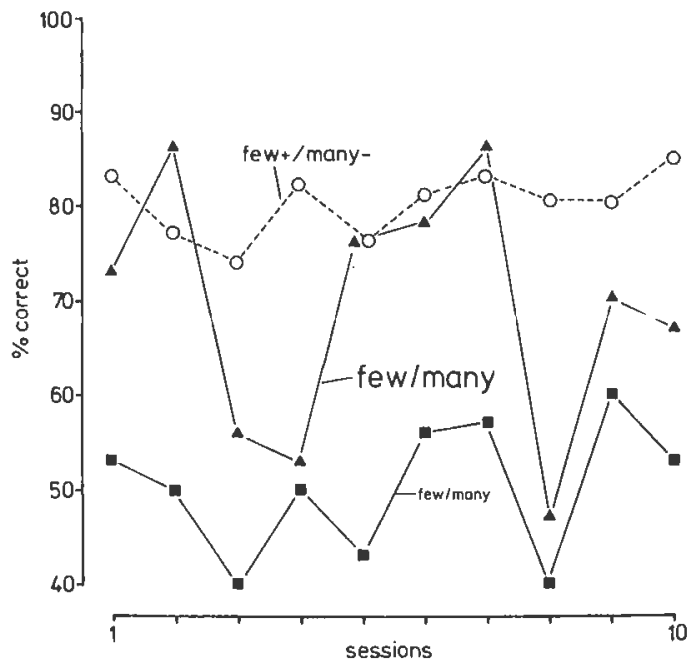

During the test in which familiar "few" stimuli were rotated there was no significant difference between performance corresponding to the three kinds of rotation and the ordinary training trials (Fig. 6; means $77.9 \%$ [Fig. 4 c], $74.1 \%$ [Fig. $4 \mathrm{~d}$ ] and $74.7 \%$ [Fig. $4 \mathrm{e}$ ] compared with ordinary trials $78.4 \% \mathrm{~F}[3,78]=$ $2.10, p>.05)$. Nevertheless there was a slight tendency for stimuli with upsidedown reflections and rotations to be slightly worse than those involving right-left reflections.

When the tests involved changes in size of both "few" and "many" shapes, both enlargement and reduction had a negative effect on the discrimination (Figs. $4 \mathrm{f}-\mathrm{g}$ and 7 ). With size reduction, the difference between test trials and ordinary trials was significant: the birds performed at chance level, showing $50.1 \%$ correct choices during test trials compared with $78.1 \%$ during training trials: $(F[1,38]=$

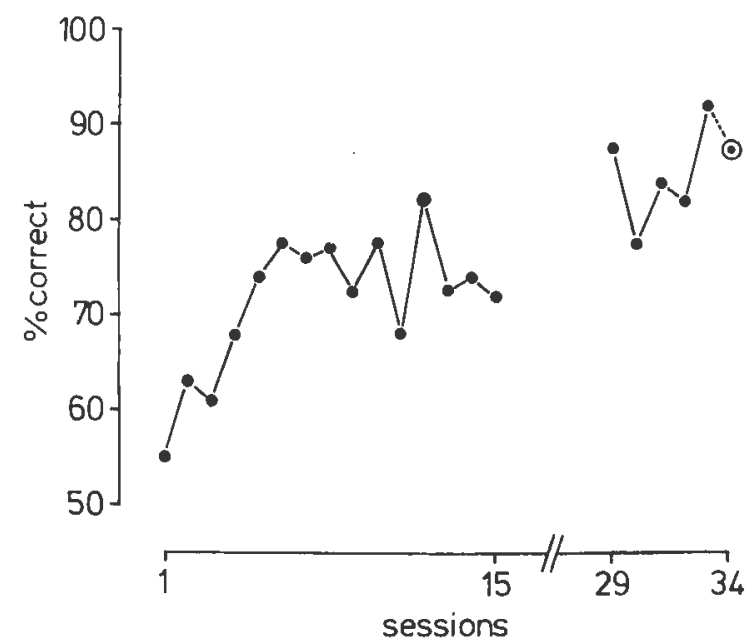

Fig. 8: Performance during the initial and terminal phases of retraining after a 6-month retention interval and result of the final memory test (double circle) 


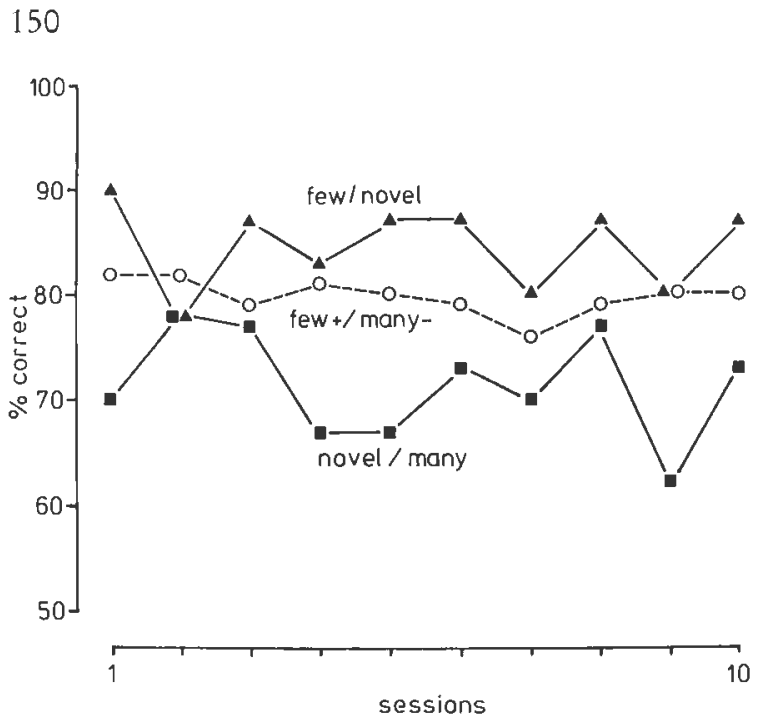

Fig. 9: Mean performance during final test sessions with quasi-novel stimuli

93.83, $\mathrm{p}<.001)$. With increased size the performance difference was less marked but still significant: $69 \%$ on test trials as compared with $81.3 \%$ on training trials: $(\mathrm{F}[1,38]=32.41, \mathrm{p}<.001)$.

After the 6-month interval, the pigeons" learning with 60 "few" stimuli and 585 "many" stimuli was rapid (Fig. 8) as compared with the original acquisition (Fig. 3). The three pigeons reached the criterion (10 consecutive sessions with an average of $80 \%$ correct responses or better) after 14, 26 and 33 sessions. On session 34 the animals werc confronted with 40 stimulus pairs made up from shapes that had not been used during retraining and which the pigeons had not seen for 222 days. The average performance was $87.5 \%$ correct (the individual pigeons yielded $82.5 \%, 87.5 \%$ and $92.5 \%$ correct choices). A binomial test showed that the proportion of correct choices was significantly different from chance $(z=8.22, p<.001)$.

In the choice test where the stimuli "many" were replaced by quasi-novel stimuli there was, as before with novel stimuli, a significant difference in favour of the test trials as compared with the training trials $(84.6 \%$ vs. $80.3 \%$; F $[1,38]=$ $8.95, \mathrm{p}<.01$; Fig. 9). In the test in which "few" stimuli were replaced by quasinovel stimuli there was a significant difference in performance in favour of the training trials $(80.1 \%$ vs. $71.3 \% ; F[1,38]=24.32, p<.001$; Fig. 9). A similar trend was noticeable in the earlier, equivalent test (compare with Figs. 4 a, b and $5)$.

\section{Discussion}

The results show firstly that pigeons can retain in memory 725 visual patterns for at least several days provided they have had fairly extensive previous exposure to them. The subjects were rather slow in the initial acquisition even though the stimuli of the "few" class were only gradually introduced. An 
unpublished attempt to train pigeons on all 725 stimuli at the same time was clearly beyond these birds' abilities. Even after 80 sessions, performance was no better than $65 \%$ correct choices.

A remarkable result arose when stimuli of the class "many" were replaced by novel stimuli, the discrimination performance was significantly better than that on trials with familiar "many" shapes in two separate tests. Novel stimuli seemed to function as super-stimuli (in loose analogy to the "super-releasers" of ethologists: MANNing 1979; compare also HOGAN et al. 1975) when replacing "many" stimuli. This result suggests that the pigeons had categorized the training stimuli into two classes: familiar (which they had seen more than 100 times) and less familiar (which they had seen only about 40 times). Completely novel, unfamiliar stimuli presumably represented extreme exemplars of the latter class facilitating the discrimination as they were more distinct from the familiar "many" stimuli. In other words discrimination performance profited from a generalization peakshift effect (HONIG \& URCUIOL.I 1981; the same effect is more recently referred to as dimensional contrast, HINSON 1988) along the familiarity/novelty dimension. It may be incidentally that because I. MoHR and S. SCHÜrgik's experiment (reported by Delius 1985) happened to take advantage of such spontaneous familiar/unfamiliar discrimination it yielded better acquisition and retention than the present one.

Humans are well-known to spontaneously order stimuli on a familiar - less familiar - unfamiliar dimension. Moreover several qualitatively different frequency of experience labels seem to attach to memories of individual items. These labels enable them to make quite precise quantitative estimates of the times they were exposed to such items (Zlichmeister \& Nyblizg 1982). The latter in particular also applies to visual stimuli (HiNTZMAN \& Rogirs 1973). The extensive animal exploration/curiosity literature suggests that species such as laboratory rats and rhesus monkeys likewise spontaneously register in long-term memory how often they were exposed to particular stimuli even though little is known as to how the count is kept (Fowli: 1965). Pigeons have not been subjects of such investigation and thus information about this kind of experience tracking is not available for them. However, since recognition of novelty is a highly adaptive competence it would be surprising if they did not also classify stimuli into the unfamiliar/familiar categories.

The pigeons of the present experiment also discriminated when novel stimuli replaced stimuli of the "few" class, indicating that they also had stored item by item the class "many" stimuli as not yielding reinforcement. This information obviously overrode the more general classification according to novelty/familiarity. If the pigeons had applied the latter classification on a relational basis they should have preferred to respond to the partly familiar "many" stimuli in preference to the completely novel. The results of both tests also suggest that stimuli of the class "few" were better memorized than those of the class "many". This might have been so because they were associated with reinforcement, they were seen more often and also because there were only 100 such stimuli as compared with 625 class "many" stimuli. In short, two different labels seem to 
have attached to the stimulus representations in memory: degrce of familiarity and association with reward/nonreward.

In Schürgi:R and Mohr's study by the way, it was the unfamiliar, novel stimuli that yielded reinforcement. The familiar stimuli did not produce reinforcement. Nonetheless it was shown that the pigeons memorized durably these latter stimuli. In the present experiment it was the "many", less-familiar stimuli that were not reinforced. Pigeons clearly also learn much about unreinforced stimuli, a fact that has been sometimes doubted (see MACKINTOSH 1974). We considered whether the pigeons might have also classified the training patterns according to the dimension fixed/variable orientation. During the training the "few" patterns always had a single orientation whereas the "many" patterns were presented in two orientations. The good results of the tests involving equivalent rotations of the "few" stimuli however are evidence against such possibility.

The tests with stimuli in non-normal orientations generally yielded good discrimination transfers. However only the "few" stimuli were presented in novel orientations, while the "many" stimuli retained the same orientations as during the training. Furthermore, the birds were accustomed to orientation variations as the "many" stimuli were routinely shown in different orientations. Still, the results do not conflict with the suggestion by Hollard \& Dilius (1982) that pigeons memorize small visual patterns largely free of orientation attributes. They are also in line with the findings of Delius \& Hollard (1987), Emmerton (1986) and Lombardi (1989). Discrimination was slightly better when tests involved right-left pattern reflections than when the stimuli appeared upside-down. This could be partly due to the fact that a proportion of the patterns used during these tests were vertically symmetrical and thus did not change in appearance when reflected. However, VAUGHAN \& GRLENE (1984) reported similar findings. They suggested that the effect might have been due to their pigeons having attended predominantly to the upper part of their relatively large pictures of large natural objects or scenes. These latter tend to have typical vertical orientations determined by gravity, but not right-left preferred orientations. We doubt that this argument applied to our much smaller stimuli that are more likely to have been seen as food-related items by the pigeons. By and large such items do not have consistent orientations in nature. Instead it may be that these birds generally find left-right mirror versions of patterns more similar than upside-down versions (but see LoHMANn et al. 1988).

The tests involving stimulus size variations led to a more drastic deterioration of discriminative behaviour, particularly when the stimuli were smaller than normal. This may at least in part be due to the fact that the patterns were necessarily degraded by size reduction (loss of detail). But no such degradation attached to the increased size test patterns, and they also led to a loss of discrimination, though not quite as much as with size reduction. PISACRETA et al. (1984), Lombardi \& Delius (1989) and Cerilli. (1989) have reported that discrimination transfer by pigeons is markedly affected by size changes. LOMBARDI \& Delius (1989) have speculated about possible reasons but none of their suggestions accounts for all the relevant findings. 
After a 6-month pause, the birds' discriminatory performance was close to chance. This superficially suggests that they had forgotten about the shapes. The fact that they very rapidly relearned to discriminate the 645 shapes selected for retraining (compare Figs. 3 and 8) however strongly indicates an at least partial retention. Furthermore, following the retraining they allocated 80 of the original training shapes, not used during retraining, to the two relevant categories with high accuracy. These test stimuli were presented for the first time after 222 days, and this further proves that the birds had not forgutten the shapes. Rather, the initial discrimination failure after the retention interval must have been due to a forgetting of some procedural component. It seems unlikely that the birds had forgotten the simultaneous discrimination paradigm as such, in view of other evidence that pigeons have an excellent memory for tasks of that nature (VAUGHAN \& GRIENE: 1984; DONAHOE \& MARRS 1982). Rather it seems likely that they had forgotten that the "few" and the "many" stimulus categories signalled respectively reward and non-reward. Once the contingencies between categories and consequences had been relearned with a subset of stimuli, this refreshed knowledge could be fully transferred to the remainder of the stimuli. This implies that at this stage the reward/nonreward labels were not directly attached to the representation of the individual stimuli but rather to the familiar/less-familiar labels associated with them.

If this tandem labeling interpretation is correct, our results also represent an instance where a categorization of stimuli existed independently of an association with particular behavioural outcomes. LEA (1984) has proposed that this should be a defining criterion for true conceptualization. A test that could have decided the issue would have been to retrain half of the birds after the rentention interval on a reversed discrimination task where "many" stimuli would have signalled reward and "few" stimuli would have signalled time-out. Had the reversed group relearned the discrimination as rapidly as the non-reversed normal group, and, furthermore, dealt with the retention test as successfully, that would have supported the above hypothesis. The results were so unexpected, though, that no such test was carried out. In any case the small number of subjects would have made results difficult to interpret. A recent, more thorough study on a different conceptualization by pigeons that was done in our laboratory incorporated this kind of testing procedure (AMELING et al., in prep.).

Neither in VAughan \& GReine.'s (1984) nor in MoHr \& SchürgirR's (Delius 1985) visual memory experiments with pigeons were there such pronounced initial difficulties with retrieval after long intervals. There are a number of procedural differences between both of these experiments and the present one so that there is not necessarily a contradiction. Both studies involved fewer stimuli and did not involve, as far as can be ascertained, a categorization of stimuli of the kind that is a prerequisite for an effect as sketched above.

However that may be, the evidence for extensive memory capacities in an avian species now available from laboratory studies generally concords with results obtained in more naturalistic settings (SHE:TTLI:WORTH 1983). Persistent and capacious memory in small-brained species presumably reflects a relatively major fitness advantage accruing from extensive and thorough knowledge about the 
environment. In a species that operates in as wide-ranging an ecological niche as the domestic pigeon does, the demand for such knowledge must indeed be pressing.

\section{Acknowledgements}

The research was supported by the Deutsche Forschungsgemeinschaft through its Schwerpunktprogramm "Physiologische Psychologie des Lernens". We are grateful to Drs. J. EMMERTON, S. E. G. LEA and an anonymous referee for comments that helped us to improve the final version of this paper. We thank I. BÜNGER and A. FRANCHINI for preparing the manuscript and the figures. The experiments were conducted while the authors were still at the Psychologisches Institut, Ruhr-Universität Bochum.

\section{Literature Cited}

Atkinson, R. C. \& Shiffrin, R. M. 1968: Human memory: A proposed system and its control processes. Psychol. Learn. Motiv.: Adv. Res. Theory 2, 89-195.

Burdyn, L. E., Noble, L. M., Shreves, L. E. \& ThOMAs, R. K. 1984: Long-term memory for concepts by squirrel monkeys. Physiol. Psychol. 12, 97-102.

CERELLA, J. 1989: Shape constancy in the pigeon: the perspective transformations decomposed. In: Pattern Recognition and Concepts in Animals, People, and Machines. (Commons, M. L., HERRnSteIN, R. J. \& Kosslyn, S. M., eds.) Lawrence Erlbaum Assoc., Hillsdale, in press.

D'Amato, M. R. 1973: Delayed matching and short-term memory in monkeys. Psychol. Learn. Motiv.: Adv, Res. Theory 7, 227-269.

- - \& WORSHAM, R. W. 1974: Retrieval cues and short-term memory in capuchin monkeys. J. Comp. Physiol. Psychol. 86, 274-282.

Delius, J! D. 1985: Cognitive processes in pigeons. In: Cognition, Information Processing and Motivation. (D'YDEWALLE, G., ed.) Elsevier, Amsterdam, pp. 3-18.

- — \& HollaRD, V. D. 1987: Orientation invariance of shape recognition in forebrain-lesioned pigeons. Behav. Brain Res. 23, 251-259.

DONAHOE, J. W. \& MARRS, D. P. 1982: 12-year retention of stimulus and schedule control. Bull. Psychon. Soc. 19, 184-186.

EMmerTON, J. 1986: The pigeon's discrimination of movement patterns (Lissajous figures) and contour-dependent rotational invariance. Perception 15, 573-588.

Fowler, H. 1965: Curiosity and Exploratory Behaviour. McMillan, New York.

GELLERMANN, L. W. 1933: Chance orders of alternating stimuli in visual discrimination experiments. J. Gen. Psychol. 42, 206-208.

Herman, L. M. 1980: Cognitive characteristics of dolphins. In: Cetacean Behavior: Mechanisms and Functions. (Herman, L. M., ed.) Wiley, New York, pp. 363-429.

HrNson, J. M. 1988: A bsolute and relative measures of dimensional contrast. J. Exp. Anal. Behav. 50, $249-260$.

HintzMan, D. L. \& Rogers, M. K. 1973: Spacing effects in picture memory. Mem. Cognition 4, 430-434.

Hogan, J. A., Kruijt, J. P. \& Frijlink, J. H. 1975: "Supernormality" in a learning situation. Z. Tierpsychol. 38, 212-218.

HOLLARD, V. D. \& DeLIUS, J. D. 1982: Rotational invariance in visual pattern recognition by pigeons and humans. Science 218, 804-806.

HonIG, W. K. 1978: Studies of working memory in the pigeon. In: Cognitive Processes in Animal Behavior. (HULSE, S. H., Fowler, H. \& HONIG, W. K., eds.) Lawrence Erlbaum Assoc., Hillsdale, pp. 211-248.

- - \& URCUIOLI, P. J. 1981: The legacy of Guttman and Kalish (1956): 25 years of research on stimulus generalization. J. Exp. Anal. Behav. 36, 405-445.

KRAEMER, P. I. \& RoBERTS, W. A. 1984: Short-term memory for visual and auditory stimuli in pigeons. Anim. Learn. Behav, 12, 275-284.

LEA, S. E. G. 1984: In what sense do pigeons learn concepts? In: Animal Cognition. (RortBlat, H. L., Bever, T. G. \& Terrace, H. S., eds,) Lawrence Erlbaum Assoc., Hillsdale, pp. $263-276$. 
Lohmann, A., Dilitus, J. D., Hollard, V. D. \& I'riesli, M. I: 1988: Discrimination of shape reflections and shape orientations by pigcons. J. Comp. Psychol. 102, 3-13.

I.OMBARD, C. 1989: Shape oddity recognition by pigeons is independent of shape orientation. Rev. Mex. Anal. Cond., in press.

_- \& Deisus, J. D. 1989: Size invariance in visual pattern recognition by pigeons. In: Pattern Recognition and Concepts in Animals, People and Machines. (Commons, M. L., Kossi.YN, S. M. \& Herrensti:IN, R. J., eds.) Lawrence Erlbaum Assoc, Hillsdalc, in press.

M^ckintosin, N. J, 1974: The Psychology of Animal Learning. Acad. Press, London.

MANNING, A. 1979: An Introduction to Animal Behaviour. Arnold, London.

NickliksnN, R. S. 1968: $\Lambda$ note on long term recognition memoly for pictorial matcrial. P'sychon Sci. 11,58 .

OISON, D. J. \& MAKI, W. S. 1983: Characteristics of spatial memory in pigeons. J. Exp. Psychol.: Anim. Behav. Proc, 9, 266-280.

Ol.TON, D. S. 1978: Characteristics of spatial memory. In: Cognitive Processes in Animal Bchavior. (Huist, S. H., Iowr.ti, H. \& HoniG, W. K., eds.) Lawrence Erlbaum Assoc, Hillsdale, pp. 342-373.

PISACRI:TA, R., POTTER, C. \& LFi:AVE, P. 1984: Matching of varying-size form stimuli in the pigcon. Bull. Psychon. Soc. 22, 591-593.

Ri:nsch, B. 1973: Gedächtnis, Begriffsbildung und Planhandlungen bei Ticren. Verlag Paul Parey, Berlin.

RINGO, J. L. \& DoTY, R. W. 1985: A macaque remembers pictures briefly viewed six months earlier. Bchav. Brain Res. 18, 289-294.

- -, LlEwINI;, J. D. \& DOTY, R. W. 1986: Comparable performance by man and macaque on memory for pictures. Neuropsychol. 24, 711-717.

ROBERTS, W. A. \& GRANT, D. S. 1976: Studies of short-term memory in the pigeon using the delayed matching-to-sample procedure. In: Processes of Animal Memory. (Mi:DIN, D. L., Robi:RTS, W. A. \& DAvis, R. T., eds.) Lawrence Errbaum Assoc., Hillsdale, pp. 79-112.

- - \& Vitdiutzin, N. VAN 1985: Spatial memory in pigeons on the radial maze. J. Exp. Psychol.: Anin, Bchav. Proc, 11, 241—260.

RoITBi.AT, H. L. 1987: Introduction to Comparative Cognition. Irreeman, New York.

ScıiUl.rR, W. 1974: Die Schutzwirkung künstlicher Batesscher Mimikry abhängig von Modellähnlichkeit und Bcuteangebot. Z. Ticrpsychol. 36, 71-127.

SCIINARTZ, B. \& REILlY, M. 1985: Long-term retention of a complex operant in pigeons. J. Exp. Psychol.: Anim. Behav. Proc. 11, 337-355.

SIIEPARD, R. N. 1967: Recognition memory for words, sentences, and pictures. J. Verb. Learn. Verb. Behav. 6, 156-163.

SIIERRY, D. I: 1984: What food-storing birds remember. Canad. J. Psychol. 38, 304-321.

SIIETTIIEWORTH, S. J. 1983: Memory in food-hoarding birds. Sci. Am. 3, 102-110.

SKINNI:R, B. I. 1950: Are thcories of learning necessary? Psychol. Rev, 57, 193-216.

SPlETCH, M. L. \& EDWARISS, C. A. 1986: Spatial memory in pigeons (Columba livia) in an open-field feeding environment. J. Comp. Psychol. 100, 266-278.

STANing, L., 1973: Learning 10,000 pictures. Qu. J. Exp. Psychol. 25, 207-222.

TREiCi IIER, R. F. 1984: Long-term retention of concurrent discriminations by monkeys. Physiol. Psychol. 12, 92-96.

VAN DI:R W WL.L, S. B. 1982: An experimental analysis of cache recovery in Clark's nutcracker. Anim. Behav. 30, 84-94.

Vaugian, W. Jr. \& Griane, S. L. 1984: Pigeon visual memory capacity. J. Exp. Psychol.: Anim. Bchav. Proc. 10, 256-271.

Wrigit, A., SAntingo, H. C., SAnds, S. F., Kindrick, D. I. \& CoOk, R. G. 1985: Memory processing of serial lists by pigcons, monkeys, and peoplc. Science 229, 287-289.

ZlenmisistiR, E. B. \& Nybi:RG, S. E. 1982: Human Memory, an Introduction to Research and Theory. Brooks/Cole, Montercy. 